\title{
A GENERALIZATION OF THE LAX EQUIVALENCE THEOREM ${ }^{1}$
}

\author{
MARTIN H. SCHULTZ ${ }^{2}$
}

This paper is concerned with a generalization of the Lax Equivalence Theorem dealing with the approximation of a $C_{0}$-semigroup in a Hausdorff, locally convex topological vector space, e.g. spaces of tempered distributions. Such spaces are of interest in the study of Cauchy problems for systems of partial differential equations with constant coefficients. Indeed, the solution of a Cauchy problem is generated by the action of a $C_{0}$-semigroup of transformations in a space of tempered distributions if and only if the Cauchy problem is regular in the sense of Petrowski, cf. [2].

Let $V$ be any locally convex topological vector space over the complex numbers. Following Yosida, [3], we have the following:

Definition 1. If $\left\{T_{t} \mid t \geqq 0\right\}$ is a family of bounded linear transformations of $V$ into itself such that

(1) $T, T_{t}=T_{t+s}, t, s \geqq 0$,

(2) $T_{0}=I$, and

(3) $\lim _{t \rightarrow s} T_{t} \nu=T_{s} \nu$ for each $s \geqq 0$ and each $\nu \in V$, then $\left\{T_{t}\right\}$ is said to be a $C_{0}$-semigroup.

Let $\left\{B_{h} \mid h>0\right\}$ be a one-parameter family of bounded linear operators in $V$.

Definition 2. The family $\left\{B_{h}\right\}$ is said to be consistent with $\left\{T_{t}\right\}$ if and only if $\left(B_{h}-T_{h}\right) T_{t} / h \rightarrow 0$ as $h \rightarrow 0$ uniformly with respect to $t$ for every compact interval of time.

Definition 3. The family $\left\{B_{h}\right\}$ is said to be convergent to $\left\{T_{t}\right\}$ if and only if $\left\{B_{h}^{n}-T_{t}\right\} \rightarrow 0$ as $n h \rightarrow t, h \rightarrow 0$.

Generalized Lax Equivalence Theorem. Let $\left\{T_{t}\right\}$ be a $C_{0^{-}}$ semigroup in $V$ and $\left\{B_{h} \mid h>0\right\}$ be a one-parameter family of bounded linear operators in $V$. If $V$ is barrelled and $\left\{B_{h}\right\}$ is convergent then the family $\left\{B_{h}^{n} \mid n h \leqq T\right\}$ is equicontinuous for all $T>0$. Conversely, if $\left\{B_{h}\right\}$ is consistent with $\left\{T_{t}\right\}$ and the family $\left\{B_{h}^{n} \mid n h \leqq T\right\}$ is equicontinuous for all $T>0$ then $\left\{B_{h}\right\}$ is convergent.

Proof. As is well known, cf. [3], the topology in a Hausdorff,

Received by the editors April 20, 1966.

1 This research was supported in part by Contract Nonr-1866 (34) for the Office of Naval Research at Harvard University.

2 Case Institute of Technology. 
locally convex topological vector space is generated by a family of seminorms $\left\{\|\|_{p} \mid p \in P\right\}$.

First let $V$ be barrelled and $\left\{B_{h}\right\}$ convergent. Then by the Uniform Boundedness Theorem, cf. [3], the family $\left\{B_{h}^{n} \mid n h<T\right\}$ will be equicontinuous if for every $\nu \in V$ the set $\left\{B_{h}^{n} \nu \mid n h \leqq T\right\}$ is bounded. Assume that there exists a $\nu \in V$, a bounded sequence $\left\{n_{i}, h_{i}\right\}$, and a seminorm $\|\cdot\|_{p}$ such that $\left\|B_{h_{j}}^{n_{i}}(\nu)\right\|_{p} \rightarrow \infty$ as $i \rightarrow \infty$. Choose a subsequence, $\left\{n_{j}, h_{j}\right\}$ such that $n_{j} h_{j} \rightarrow t$ as $j \rightarrow \infty$. Then $\left\|B_{h_{j}}^{n_{j}}(\nu)\right\|_{p} \leqq\left\|\left(B_{h_{j}}^{n_{j}}-T_{t}\right) \nu\right\|_{p}$ $+\left\|T_{t} \nu\right\|_{p} \leqq K<\infty$. But this is a contradiction.

Second, let $\left\{B_{h}\right\}$ be consistent with $\left\{T_{t}\right\}$ and the family $\left\{B_{h}^{n} \mid n h \leqq T\right\}$ be equicontinuous for all $T>0$. Then $\left\{B_{h}\right\}$ will be convergent if for any $\nu \in V$, any sequence $\left\{n_{i}, h_{i}\right\}$ such that $h_{i} \rightarrow 0$ and $n_{i} h_{i} \rightarrow t>0$, and any seminorm $\|\cdot\|_{p}, \quad\left\|\left(B_{h_{i}}^{n_{i}}-T_{t}\right) \nu\right\|_{p} \rightarrow 0$. But $\left\|\left(B_{h_{i}}^{n_{i}}-T_{t}\right) \nu\right\|_{p} \leqq\left\|\left(B_{h_{i}}^{n_{i}}-T_{n_{i} h_{i}}\right) \nu\right\|_{p}+\left\|\left(T_{n_{i} h_{i}}-T_{t}\right) \nu\right\|_{p}$.

It is easy to verify that

$$
\begin{aligned}
\left\|\left(B_{h_{i}}^{n_{i}}-T_{n_{i} h_{i}}\right) \nu\right\|_{p} & \leqq h_{i} \sum_{k=0}^{n_{i}-1}\left\|B_{n_{i}}^{k}\left(\frac{B_{h_{i}}-T_{h_{i}}}{h_{i}}\right) T_{\left(n_{i}-1-k\right) h_{i} \nu}\right\|_{p} \\
& \leqq c h_{i} \sum_{k=0}^{n_{i}-1}\left\|\left(\frac{B_{h_{i}}-T_{h_{i}}}{h_{i}}\right) T_{\left(n_{i}-1-k\right) h_{i} \nu}\right\|_{q}
\end{aligned}
$$

for some $c>0$ and some seminorm $\|\cdot\|_{q}$ because of equicontinuity. Given $\epsilon>0$, consistency implies that there exists an $I_{1}>0$ such that

$$
\left\|\left(\left(B_{h_{i}}-T_{h_{i}}\right) / h_{i}\right) T_{\left(n_{i}-1-k\right) h_{i}} \nu\right\|_{q} \leqq \epsilon / 2 c(1+t)
$$

and $h_{i} n_{i} \leqq 1+t$ for all $0 \leqq k \leqq n_{i}-1$ and $i \geqq I_{1}$. Furthermore, because $\left\{T_{t}\right\}$ is a $C_{0}$-semigroup there exists an $I_{2}>0$ such that $i \geqq I_{2}$ implies $\left\|\left(T_{i_{i} h_{i}}-T_{t}\right) \nu\right\|_{q} \leqq \epsilon / 2$. Thus,

$$
\left\|\left(B_{h_{i}}^{n_{i}}-T_{t}\right) \nu\right\|_{p} \leqq c h_{i} n_{i}(\epsilon / 2 c(1+t))+\epsilon / 2 \leqq \epsilon
$$

for all $i \geqq \max \left(I_{1}, I_{2}\right)$. QED.

\section{REFERENCES}

1. R. D. Richtmyer, Difference methods for initial-value problems, Interscience, New York, 1957.

2. M. H. Schultz, Difference methods for Cauchy problems in $S^{\prime}, \mathrm{J}$. Math Mech. (to appear).

3. K. Yosida, Functional analysis, Springer-Verlag, Berlin, 1965.

CASE Institute of TeChNology 